\title{
SÍTIO RS - LN - 01 \\ CAPÃO DA AREIA, OSÓRIO, RS
}

Sérgio Leite*

\section{1 - COMENTÁRIOS INICIAIS}

Este texto visa descrever uma pesquisa arqueológica levada a efeito em Osório, RS, zona de domínio do complexo lagunar costeiro rio-grandense.

O sítio localiza-se na propriedade do Sr. Osmar Martins de Oliveira; dista $4.200 \mathrm{~m}$ do entroncamento da RS-30 com a estrada que conduz à Fazenda Ipê e Rincão dos Veados; a localidade denomina-se Capão da Areia. A propriedade está situada a esquerda da Usina de Compostagem de resíduos sólidos da Prefeitura Municipal de Osório, popularmente denominado "lixão da prefeitura". O acesso da propriedade encontra-se a $32 \mathrm{~m}$ após a porteira e avançando-se mais $260 \mathrm{~m}$, encontramos o sítio arqueológico.

Os resultados apresentados, por serem parciais, deverão ser complementados por pesquisas futuras e por análises dos materiais já coletados e devidamente guardados em instituições de pesquisa.

Por ser um trabalho realizado também por alunos, merece ser divulgado enquanto didática de arqueologia.

- Arqueólogo do Museu Antropológico do Rio Grande do Sul, professor da FACOS, da FAPA e mestrando em Arqueologia no CEPA/PUC-RS.

Estudos Ibero-Americanos. PUCRS, v.XXI, n.2, p. 33-62, dezembro, 1995 


\section{2 - AGRADECIMENTOS}

- Ao Sr. Osmar Martins de Oliveira, proprietário da terra, que permitiu o acesso ao sítio;

- À FACOS (Faculdade de Ciências e Letras de Osório) que respaldou financeiramente o projeto bem como forneceu condições para a análise laboratorial;

- Ao MARS (Museu Antropológico do Rio Grande do Sul) que forneceu apoio institucional;

- Luciano Garófalo Leite, que nos auxiliou na $2^{\underline{a}}$ etapa do trabalho de campo;

- Arienei Erian Abreu, Técnico em Assuntos Culturais do MARS auxiliou na análise laboratorial;

- Ronald Santiago de Castro, datilografou o original;

- Rosa Adriana Andriotti Blasckesi, estagiária que confeccionou os desenhos e as tabelas;

- André Jacobus, diretor do MARSUL (Museu Arqueológico do Rio Grande do Sul) que gentilmente cedeu-nos informações sobre o material depositado na instituição (Trabalhos de E. Müller e Juçara Lousada).

- Aos alunos do $3^{\circ}$ semestre de história da FACOS, 1994, que viram na pesquisa algo mais que uma exigência didática;

- A todas as pessoas que tornaram possível a realização deste trabalho.

\section{3 - PARTICIPANTES DA PESQUISA}

\section{1 - Museu Antropológico do RS}

\section{2 - Faculdade de Filosofia, Ciências e Letras de Osório}

\section{4 - CARACTERÍSTICAS DA REGIÃO}

O sítio arqueológico RS-LN-01 está localizado no município de Osório, litoral Norte do Estado, nas coordenadas de $50^{\circ} 05^{\prime}, 70^{\prime \prime}$ de 
longitude Oeste e de $29^{\circ} 55^{\prime} 40^{\prime \prime}$ de latitude sul. A região é caracterizada basicamente como oriunda de depósitos praiais inter-marés, parcialmente recobertas por depósitos eólicos de dunas litorâneas (Tomazelli, 1984).

A análise geológica do sítio nos indica estar ele localizado em uma formação quartenária, Grupo Patos, formação Itapuã, constituído de areias eólicas pleistocênicas (Carraro, 1974).

Conforme uma autora (Tocchetto, 1987: 224/225), "A paisagem do norte da planície costeira do Rio Grande do Sul é, e o era na época da ocupação indígena, composta por vários ambientes distintos mas em completa harmonia e equilíbrio. O Oceano Atlântico, a faixa arenosa litorânea, a zona de campo, intercalada por mata, as colinas e os morros, as áreas de banhados e lagoas e, ainda a Serra Geral, oferecem perfeitas condições ecológicas para a existência e desenvolvimento de espécies vegetais e animais em grande variedade. Os grupos caçadores-coletorespescadores tinham a sua disposição, assim, alimentos riquíssimos, oriundos destes diferentes nichos ecológicos, proporcionando uma alimentação saudável e equilibrada.

O homem pré-histórico, habitante da costa litorânea, tinha como dieta alimentar os produtos da pesca que poderia ser realizada com redes e anzóis (...) tanto no mar, como nas lagoas circundantes, moluscos marinhos, lacustres e dos manguezais e certos tipos de vegetais obtidos pela coleta, e mamíferos, aves, répteis, pela caça.

Este ambiente natural, composto por um mosaico de paisagens, foi selecionado pelo indígena em decorrência de uma série de necessidades e exigências do grupo. Além de um meio natural, rico em alimentos, ele também oferecia matéria-prima para a elaboração e confecção de implementos necessários para a vida cotidiana do grupo...

Conforme os dados levantados sobre a evolução físico-geográfica da planície costeira nos últimos 500.000 anos, o período em que os grupos humanos poderiam ter se instalado sem sofrer com as mudanças seria já no final do holoceno $( \pm 4.000$ A.P. $)$. Esta data corresponde a uma fase de estabilização, tanto dos processos transregressivos marinhos, como do clima. Em decorrência de um ambiente mais estável, a fauna e a flora desenvolver-se-iam sem interferências e os grupos pré-históricos encontrariam condições favoráveis para a ocupação... Aspectos da flora, da fauna, do solo, dos afloramentos rochosos e das paisagens físico-geográficas fazem parte de uma pesquisa que busca uma análise global do 
homem enquanto indivíduo e enquanto grupo, inserido num meio ambiente que exerce forte pressão sobre ele."

\section{5 - AS PESQUISAS ARQUEOLÓGICAS NA REGIÃO'}

\section{1 - As pesquisas anteriores}

5.1.1 - Desconhecemos quaisquer trabalhos na década de 50 ou anteriores

5.1.2 - Na década de 60 , novembro de 65 e janeiro de 66, E. Müller encontrou-se e escavou o sítio "Passo Fundo", RS-LN-16, propriedade de Luiz Freitas (Lulú). Localiza-se a 3.100m da faixa de Tramandaí, no local chamado Capão da Areia. Trata-se de 10 concentrações de material, espalhada em área de $60 \times 870 \mathrm{~m}$. 0 autor afirma que "(...) a área é excessiva para um único sítio e, em examinando o mapa, percebe-se agrupamentos constituindo-se talvez cada um, um sítio em particular."

Para este sítio, há duas datações:

SI-410 - 1.430 A.D.

e

SI-411 - 1.410 A.D.

Foram encontrados 83 líticos, 1968 fragmentos cerâmicos e 10 vasilhas cerâmicas inteiras.

Se o sítio (ou sítios) encontra-se no Passo Fundo fica mais longe. Por isto, a informação "Capão da Areia" é pouco confiável. Assim sendo, não temos certeza da exata localização do sítio.

5.1.3 - Em março/66, o mesmo autor encontra, mais ao norte, o sítio RS-EN-35 (2 núcleos) em Morro Alto, Capão da Canoa, com duas datações:

$$
\begin{aligned}
& \text { SI-412-1.080 A.D. } \\
& \text { e } \\
& \text { SI-413 - } 880 \text { A.A. }
\end{aligned}
$$

1 A maioria das informações contidas neste item foram fornecidas por A. Jacobus, a quem agradecemos. 
Foram encontrados 50 líticos, 819 fragmentos cerâmicos e 7 vasilhas.

Na década de 70, Juçara Louzada trabalhou na área, porém desconhecemos os resultados e a localização dos sítios.

5.1.4 - Também nos anos 70, José Brochado (Com. person) e Miguel Bombim recolheram material de um grande sítio Guarani, dentro do Parque Osório, a sul-suleste do sítio em pauta.

\section{2 - A pesquisa atual: histórico}

Há vários semestres estávamos sentindo, da parte dos alunos, um interesse de estudar arqueologia não só enquanto disciplina teórica componente do elenco de disciplinas da graduação em história da FACOS, mas como a possibilidade de realização de um trabalho prático. Em março/93 o aluno Valdir M. Saturnino Filho levou para a sala de aula alguns cacos oriundos do sítio. Segundo ele, o sítio estava ameaçado de destruição, porque o proprietário dedicava-se a extrair areia do local. Após contactado, o proprietário concordou em não destruir o sítio e permitiu o acesso aos alunos.

Os fatos acima foram os detonadores do projeto "Conhecendo o ontem para termos amanhã: projeto de pesquisa arqueológica no sítio Capão da Areia, RS-LN-01, Osório, RS". Aprovado pelo IBPC, foi autorizado sua escavação conforme portaria $\mathrm{n}^{\circ} 281$, de 30/agosto/93, publicada no D.O.U de 31/agosto/93.

Além de realizar o salvamento do sítio o projeto comprometeu-se a realizar com alunos um trabalho de campo e de laboratório, obrigando-se também a socializar os resultados.

Em 9/abril/94 os alunos do $3^{2}$ semestre de história da FACOS realizaram o trabalho de campo. Posteriormente, em 30/abril, o professor da disciplina e seu filho finalizaram o trabalho.

Durante o trabalho de campo, as atividades foram filmadas por um aluno. O vídeo está à disposição para atividades didáticas-pedagógicas. 


\section{6 - A METODOLOGIA DO TRABALHO}

\section{1 - Em campo}

No decorrer do $1^{\circ}$ semestre de 1993 , os alunos receberam instruções teóricas sobre escavações arqueológicas; ao organizarmos o trabalho de campo, a turma foi dividida em várias equipes, cada uma delas com atribuições específicas.

Uma das equipes ficou responsável pela aquisição de mapas, contato com o proprietário, transporte, etc.

A segunda equipe realizou a topografia do terreno bem como os desenhos, a plotação do sítio no mapa e a marcação do ponto "0".

A terceira equipe responsabilizou-se pela coleta de material na porção esquerda do sítio, onde foi praticada a técnica de "Survey". Aárea foi dividida em cinco setores, sendo que cada setor de caminhamento foi confiado a dois alunos, responsáveis pela coleta, etiquetação e embalamento individualizado do material.

A quarta equipe realizou o piqueteamento do sítio (malha de $1 \mathrm{x}$ $1 \mathrm{~m})$ compreendendo aí também a pequena porção do piso ocupacional ainda restante, do qual foi retirada uma porção para análise do solo.

Outra equipe encarregou-se de coletar, dentro da malha, o material encontrado. Após embalado, foi levado para as dependências da FACOS, onde, posteriormente a sexta equipe realizou a análise laboratorial.

\section{2- Em laboratório}

Em sala de aula, a equipe dedicou-se a:

1 - Limpeza de todas as peças; ${ }^{2}$

2 - Identificação tecno-tipológica;

3 - Quantificação;

4 - Organização dos dados;

5 - Manipulação dos dados;

6 - Confecção de gráficos, tabelas e similares;

2 Por se tratar de uma simulação de laboratório, levada a efeito dentro da sala de aula, foram selecionadas e manipuladas apenas algumas peças; as restantes foram processadas no laboratório do MARS. 
7 - Reconstituição das formas cerâmicas a partir dos cacos;

8 - Redação do texto.

\section{7 - ANÁLISE DO MATERIAL OBTIDO}

\section{1 - O material cerâmico}

A terminologia usada neste capítulo encontra-se fundamentalmente em La Sálvia \& Brochado, 1989.

A pesquisa deste sítio nos revelou a existência de 5.746 cacos cerâmicos divididos nas diversas quadrículas e classificados segundo as variantes abaixo:

1 - Cacos cerâmicos sem trabalho, isto é, simples em ambos os lados;

2 - Cacos cerâmicos com superfícies pintadas;

2.1 - Lado externo: listras vermelhas sobre fundo branco. Lado interno: simples.

2.2 - Lado externo: pintura branca. Lado interno: simples.

2.3 - Lado externo: pintura branca. Lado interno: listras vermelhas sobre fundo branco.

2.4 - Lado externo: pintura vermelha. Lado interno: simples.

2.5 - Lado externo: simples. Lado interno: listras vermelhas sobre fundo branco.

2.6 - Lado externo: simples. Lado interno: pintura branca.

2.7 - Lado externo: simples. Lado interno: pintura vermelha.

2.8 - Lado externo: pintura branca. Lado interno: pintura branca.

2.9 - Lado externo: pintura vermelha; Lado interno: pintura vermelha.

3 - Cacos cerâmicos com movimentação de massa por afundamento, isto é, porções de massa foram afundadas pela pressão das unhas da artesã.

3.1 - Lado externo: ungulado. Lado interno: simples.

3.2 - Lado externo: corrugado/ungulado. Lado interno: simples.

3.3 - Lado externo: corrugado/ungulado. Lado interno: listras vermelhas sobre fundo branco. 
4 - Cacos cerâmicos com movimentação de massa por amassamento, isto é, porções de massa foram amassadas pela ação dos dedos da artesã, ao empurrar a massa ainda plástica.

4.1 - Lado externo: corrugado. Lado interno: simples.

4.2 - Lado externo: corrugado. Lado interno: pintura branca.

4.3 - Lado externo roletado. Lado interno: listras vermelhas sobre fundo branco.

5 - Cacos cerâmicos que, por suas dimensões reduzidas ou estado de erosão foram agrupados como "não-classificados".

Para maiores esclarecimentos, consultar o anexo 3, que apresenta o total de cada quadrícula na seguinte ordem:

- cacos correspondentes à borda da vasilha;

- cacos correspondentes ao corpo da vasilha;

- cacos correspondentes à base da vasilha;

- soma dos cacos.

Ao distribuirmos os diversos tipos pelas quadrículas, obtivemos o anexo 6, esclarecedor no tocante ao padrão de dispersão cerâmica. Entretanto, devemos levar em conta que estamos trabalhando em um sítio semi-destruído, portanto as interferências devem ser relativizadas. Para facilitar a compreensão, aglutinamos todo o material cerâmico em quatro blocos a saber:

- cerâmica simples;

- cerâmica com pintura;

- cerâmica com movimentação de massa por afundamento;

- cerâmica com movimentação de massa por amassamento.

Os cacos "não classificados" foram desconsiderados.

Ao quadricularmos o sítio, reservamos o catálogo 163 para peças eventualmente obtidas para quadriculamento, no entorno da área. Como tal não ocorreu, o catálogo não foi acionado.

No que tange ao item "formas" seguimos o modelo já publicado em SCHMTIZ, 1990; o sítio forneceu as formas 1A, 1B, 1C, 1D, 1D1, 1E, 1G, 2Ba, 4A, 6A, 9A, P1, P3, P4.1, P5.1 e P6. A reconstituição foi algo problemático, porque não encontramos nenhuma vasilha inteira ou semiinteira, e também os cacos encontrados apresentaram, via de regra, pequenas dimensões.

Do ponto de vista da confecção, a técnica de manufatura é o acordelado, cujos roletes característicos são facilmente identificáveis nas 
fraturas dos cacos. Outrossim, observamos em alguns cacos a presença de bolhas de ar. A massa cerâmica apresenta grãos de quartzo branco de muito finos a médio $(0,1$ a $0,3 \mathrm{~mm})$ bem distribuídos em pasta homogênea, argilo-arenosa. Queima: incompleta, no máximo $8,0 \mathrm{~mm}$, sendo que a maioria situa-se em torno de 0,5 a $2,0 \mathrm{~mm}$ de queima, formando assim um núcleo escuro entre paredes ocre-pardacentas-acinzentadas. As superfícies apresentam um alisamento regular. A face interna, em geral, apresenta um melhor alisamento do que a externa. Isto se deve a uma fina camada de barbotina.

Pelas datações obtidas por Müller e pela não existência de cerâmica escovada, acreditamos que este sítio seja relativamente antigo, ao menos próximo e anterior à chegada dos europeus. Sobre a não presença de cerâmica escovada, consultar BROCHADO, 1980.

\section{2 - O material lítico}

O sítio RS-LN-01 forneceu 25 peças líticas, sendo que 13 , ou seja, $52 \%$ são peças cuja matriz é arenito e as restantes 12 peças (48\%) são basalto.

As peças distribuíram-se da seguinte forma:

Peça/№ Quadrícula

$1 \ldots \ldots 165$

$2 \ldots \ldots 167$

$3 \ldots \ldots 168$

$4 \ldots \ldots \ldots 170$

$5 \ldots \ldots \ldots 175$

$6 \ldots \ldots \ldots 177$

$7 \ldots \ldots \ldots 179$

$8 \ldots \ldots \ldots 182$
Peça/№ Quadrícula

9........ 183

$10 \ldots \ldots . . . . .207$

$11 \ldots \ldots 208$

$12 \ldots \ldots \ldots 210$

$13 \ldots \ldots \ldots 215$

$14 \ldots \ldots \ldots 215$

$15 \ldots \ldots \ldots 217$

$16 \ldots \ldots \ldots 198$
Peça/No Quadrícula

$17 \ldots \ldots \ldots 158$

$18 \ldots \ldots \ldots 158$

$19 \ldots \ldots \ldots 158$

$20 \ldots \ldots \ldots 158$

$21 \ldots \ldots \ldots 159$

$22 \ldots \ldots \ldots 159$

$23 \ldots \ldots \ldots 159$

$24 \ldots \ldots \ldots 160$

$25 \ldots \ldots \ldots 160$

Ao plotarmos as peças sobre o quadriculamento, não obtivemos nenhum resultado consistente. 
As peças foram agrupadas conforme segue:

\begin{tabular}{|c|c|c|c|}
\hline Variáveis & Descrição & $\begin{array}{l}N^{\circ} \text { de } \\
\text { Peças }\end{array}$ & $\begin{array}{l}\text { Percen- } \\
\text { tual }\end{array}$ \\
\hline A & $\begin{array}{c}\text { - Porção de arenito-instrumento } \\
\text { passivo (alisador/afiador) }\end{array}$ & 13 & $52 \%$ \\
\hline B & $\begin{array}{l}\text { - Porção de basalto com vesículas } \\
\text { amidalóides, sem sinal de uso }\end{array}$ & 2 & $8 \%$ \\
\hline $\mathrm{C}$ & - Basalto colunar, sem sinal de uso & 6 & $24 \%$ \\
\hline $\mathrm{D}$ & $\begin{array}{l}\text { - Basalto partido por ação térmica } \\
\text { (Termófora) }\end{array}$ & 3 & $12 \%$ \\
\hline $\mathrm{E}$ & $\begin{array}{l}\text { - Lasca cortical com plataforma } \\
\text { esmagada }\end{array}$ & 1 & $4 \%$ \\
\hline
\end{tabular}

Analisando estes dados e os apresentando em forma gráfica, temos (ver gráfico abaixo):

Ao analisarmos estes dados, um fato nos chama a atenção, qual seja a marcante presença de fragmentos de arenito, oriundos de alisadores e/ou afiadores. Tal fato nos remete ao seguinte: ou os habitantes desta casa comunal Guarani davam ênfase ao trabalho em instrumentos ósseos - e a pesquisa não confirma isto - ou construíam implementos em pedra polida, que pelo seu chamativo visual foram objeto de coleta selecionada por parte de curiosos que anteriormente visitaram o sítio.

A presença de termóforas confirma a hipótese de estarmos trabalhando um espaço habitacional, assinalado pela presença da evidência de uma tecnologia de cocção alimentar. Aliás, o elevado número de cacos cerâmicos corrobora esta afirmação.

No que tange à fonte de matérias-primas, o sítio ocupa um lugar privilegiado, pois a partir dele o material lítico pode ser obtido em um raio de poucos quilômetros.

Por outro lado, o baixo número de implementos líticos pode estar associado ao uso massivo de instrumentos em madeira, cuja durabilidade é reconhecidamente problemática. 
Analisando estes dados e os apresentando em forma gráfica, temos:

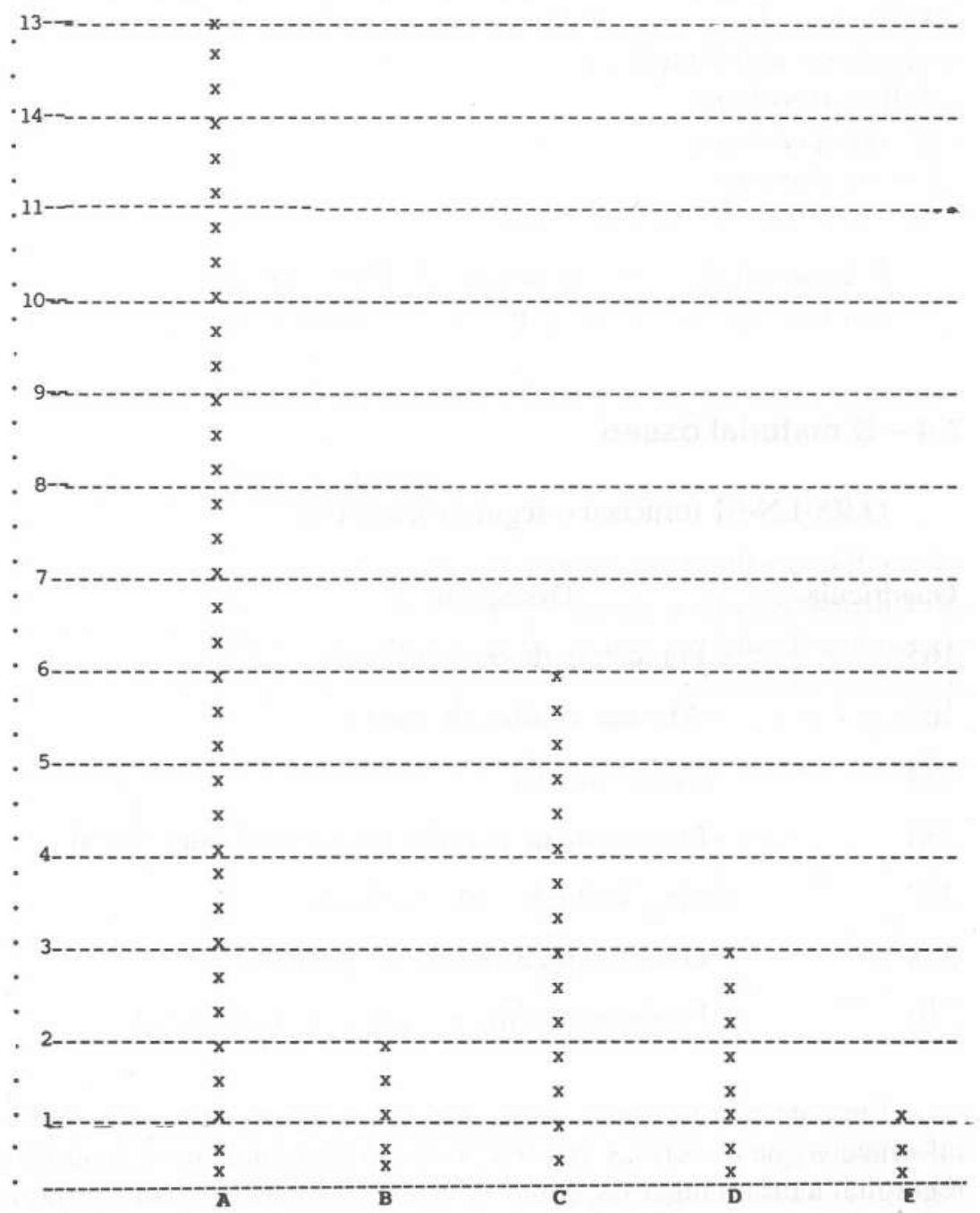




\section{3 - O material conchífero ${ }^{3}$}

Os restos de bivalves encontrados estavam em péssimo estado de conservação, o que dificultou sobremaneira o cálculo de indivíduos e sua identificação. Foram resgatadas carapaças de 28/30 indivíduos, pertencentes às seguintes espécies:

- Tellina Brasiliana

- Donax Hanleyanus

- Lucina Pectinata

- Olivancillaria vesica auricularia

Foi encontrado também um eixo de Megalobullinus.

Em nenhum caso encontramos valvas articuladas.

\section{4-O material ósseo ${ }^{4}$}

O RS-LN-01 forneceu o seguinte material:

Quadrícula

165

167

174

183

207

208

210
Descrição

- Fragmento de costela bovina

- Maxilar erodido de roedor

- Crânio de roedor

- Fragmento de maxilar de gambá (DIdalphis SP)

- Fragmento de vértebra de ovino

- Osso fragmentado de ave (diáfise)

- Fragmento muito erodido, não identificado

Em conversa informal com o biólogo Joaquim Abuchaim, fomos informados que as corujas, em seu processo de alimentação, costumam regurgitar a massa ingerida; como até a presente data existem corujas na regiẩo, os ossos oriundos de roedores - componentes da dieta alimentar

3 Ver Rios, 1985.

4 Ver Silva, 1984 e Gazzaneo et al., 1989. 
das corujas - podem ser bem recentes. Da mesma forma, os demais elementos ósseos encontrados nos apontam para o momento atual.

Se a hipótese anteriormente aventada - o sítio foi percorrido por curiosos e as peças com um visual interessante foram já recolhidas estiver correta, então peças ósseas com evidências de trabalho humano poderiam ter existido no sítio, em momento anterior ao trabalho de campo.

\section{5 - O material corante}

Foram encontradas porções de hematita, a maioria delas com evidências de raspagem. Nós as encontramos nas quadrículas 179, 185, 191, 200, 205 e 209.

\section{8 - AS PRÓXIMAS ETAPAS}

8.1 - Transformar o trabalho de campo em prática cotidiana dos próximos semestres. Pelo saldo altamente positivo da experiência, estamos convencidos do acerto da escolha: doravante a prática de campo será parte componente da carga curricular dos alunos do curso de graduação em história da FACOS. Tornou-se evidente que a prática de campo e a manipulação de peças deram aos alunos uma outra dimensão de prática arqueológica.

8.2 - Priorizar a divulgação dos resultados obtidos nos próximos trabalhos. Na medida em que obtivermos mais resultados de trabalhos de campo e de laboratório, é nossa intenção divulgar os resultados obtidos, único caminho de tornarmos a pesquisa útil à coletividade.

8.3 - Varredura na área. Para os próximos trabalhos, imaginamos expandir a área de ação, procurando novos sítios vizinhos e investigando áreas periféricas.

8.4 - Estabelecer mecanismos de divulgação junto ao grande público. Pretendemos usar os elementos da mídia da região para divulgar o trabalho e os resultados obtidos. Acreditamos que isto nos fornecerá novos sítios e, mais importante que tudo, funcionará como um canal de conscientização para a comunidade.

8.5 - Refinar a análise. Pelo incentivo que estamos recebendo da FACOS e pela perspectiva de modernização do MARS, acreditamos que 
dentro de pouco tempo, poderemos manejar os dados obtidos usando computação gráfica e informatização dos dados, o que, sem dúvida, dará um "Plus" aos resultados.

8.6 - Analisar o material do sítio depositado em outras instituições. Usando a mesma metodologia, desejamos manipular as peças que foram coletadas em trabalhos anteriores, por outros pesquisadores. Queremos obter dados que, somados aos nossos, tornem mais claros os processos ocorridos no RS-LN-01.

\section{9 - CONCLUSÕES}

9.1 - Pela análise do material cerâmico obtido, conclui-se que estamos frente a um sítio Guarani, conforme a bibliografia concernente;

9.2 - A Região é arqueologicamente rica, merece mais pesquisas;

9.3 - Novas pesquisas deverão ser efetuadas, não só para "salvar" sítios ameaçados, mas atendendo problemáticas específicas (alimentação do grupo, domínio de nichos ecológicos, etc.);

9.4-As pesquisas deverão ser mais divulgadas, para que uma larga fatia da população tenha acesso aos dados;

9.5 - Do ponto de vista didático, este sítio forneceu uma fértil experiência;

9.6 - As prefeituras, museus municipais, faculdades regionais e afins têm a grande responsabilidade de assumir, financiar e divulgar as pesquisas arqueológicas, para que as comunidades se sintam responsáveis pelo patrimônio arqueológico;

9.7 - Para o sul do Brasil, as datações arqueológicas nos mostram a cerâmica escovada só aparecendo em determinado momento, muito próximo do contato. Sua não presença absoluta, nos coloca o sítio em momento cronológico anterior. Outro dado que nos aponta na mesma direção é o seguinte: todo o material não indígena encontrado no sítio (ossos de bovinos, de ovinos) permitem supor que seu aparecimento no sítio ocorreu após a desocupação, portanto é plausível supor que o sítio foi ocupado antes da penetração branca na região;

9.8 - Lutar para efetivamente estabelecer e fazer cumprir uma legislação clara e atuante sobre sítios arqueológicos, sua conservação, manipulação, mapeamento, etc. 


\section{0 - BIBLIOGRAFIA}

BROCHADO, José J. J. Proença. Desarrollo de la tradición cerámica Tupiguarani. (AD. 500 - 1800) Segunda parte de "Migraciones que difundieron la tradición Alfarera Tupiguarani - Relaciones, 1973: 7-39. UFRGS, IFCH, Depto de C. Sociais, Gab. de Arq. Public. n. 3, Porto Alegre, 65 p. + anexos, 1980.

CARRARO, Clóvis Carlos et al. Mapa geológico do Estado do Rio Grande do Sul. Escala: 1: 1.000.000. Mapa № 8. Instituto de Geociências, Porto Alegre: UFRGS, 29 p. + mapa, out. 1974 .

GAZZANEO, Marta et al. $O$ uso da fauna pelos ocupantes do sítio de Itapera (Torres). Arqueologia do Rio Grande do Sul, Brasil, Documentos, 03, Instituto Anchietano de Pesquisa, São Leopoldo: UNISINOS, p. 123/144, 1989.

RIOS, E. C. Seashells of Brazil. Fundação cidade do Rio Grande, Museu Oceanográfico, Rio Grande, RS, v. 12, 331 p., 1985.

LA SALVIA, Fernando \& BROCHADO, José J. J. Proença. Cerâmica Guarani. Porto Alegre: Posenato Arte e Cultura, Porto Alegre, 175 p., 1989.

SCHMTIZ, Pedro Ignácio, S.J. et al. Uma aldeia Guarani. Projeto Candelária, RS Arqueologia do Rio Grande do Sul, Brasil. Documentos, Instituto Anchietano de Pesquisa, São Leopoldo: UNISINOS, 135 p., 1990.

SILVA, Flávio. Mamíferos silvestres do Rio Grande do Sul. Porto Alegre: Fundação Zoobotânica 244 p., 1984.

TOCCHETTO, Fernanda Bordin. "O meio ambiente e os grupos pré-históricos do norte da planície costeira do RS: O sítio arqueológico de Itapeva". Porto Alegre: VERITAS, n. 32 , n. 126 , p. $217-229$, jun., 1987.

TOMAZELLI, Luiz José et al. Masa geológico Folhas Osório e Tramandai. N ${ }^{\text {os }}$ (SH-22-X-C-V-3 e M/2972/3) e (SH-22-X-C-V4 e M/2972/4). UFRGS, Instituto de Geociências, Centro de Estudos de Geologia Costeira e Oceânica - CECO. Porto Alegre/RS, 1984.

\section{1 - ANEXOS}

- Anexo 1: Mapa localizando a porção enfocada dentro do Rio Grande do Sul e datalhamento da região.

- Anexo 2: Croquis do sítio mostrando seu quadriculamento e a porção do piso habitacional ainda restante.

- Anexo 3: Quadro dos totais cerâmicos do sítio.

- Anexo 4: Formas cerâmicas encontradas no sítio.

- Anexo 5: Formas cerâmicas encontradas no sítio.

- Anexo 6: Quadro de distribuição dos tipos cerâmicos no sítio.

- Anexo 7: Listagem dos alunos do 3 semestre de História da

FACOS, que participaram do trabalho de campo e/ou laboratório.

- Anexo 8: Fotos do trabalho de campo. 


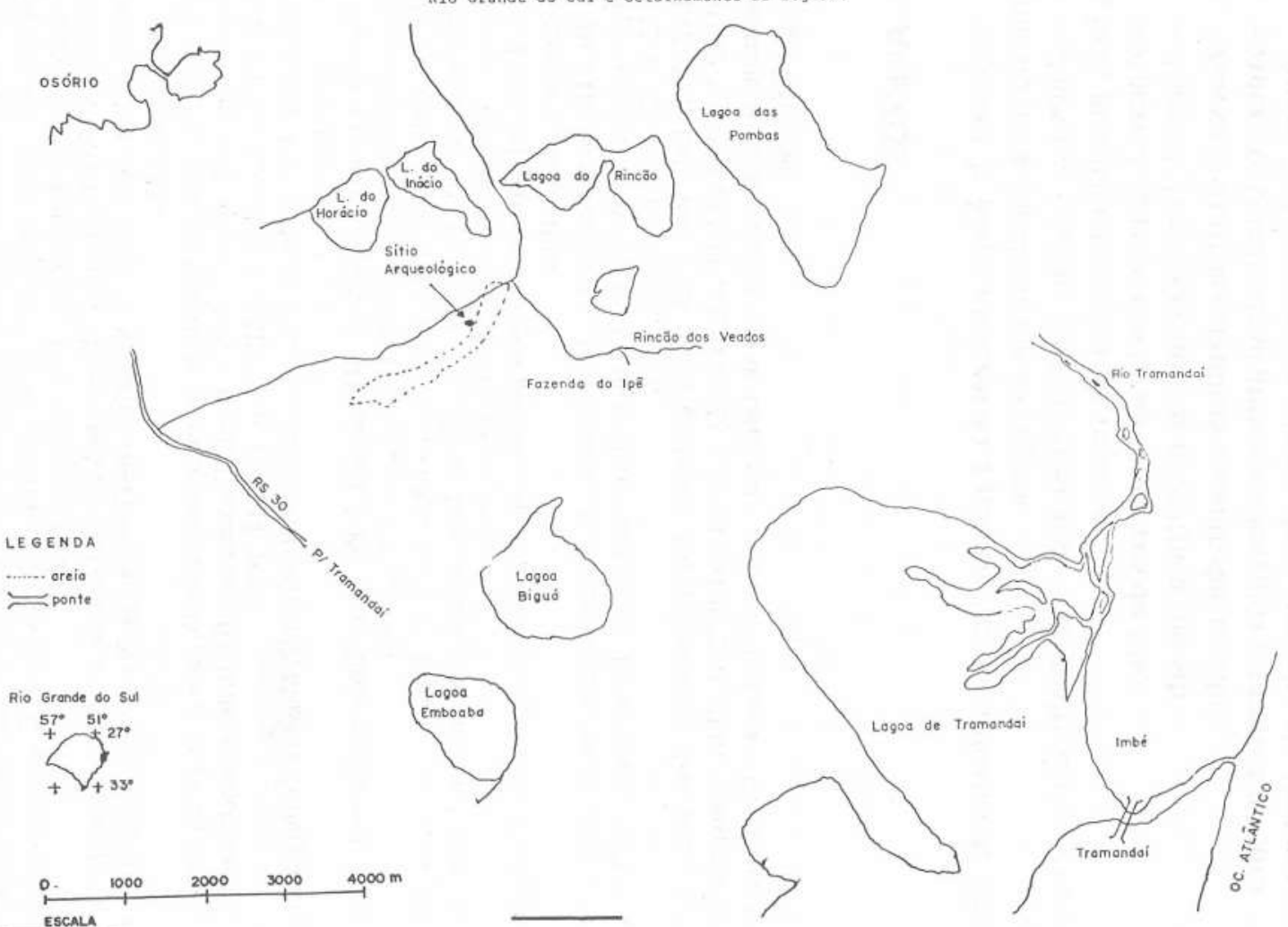


Anexo $2: 1$

SiTIO RS-LN.OI

Croqui do sitio mostrando seu quadriculamento e a porçāo

do piso habitacional ainda restante.

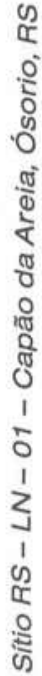

199

$\frac{8}{8}$

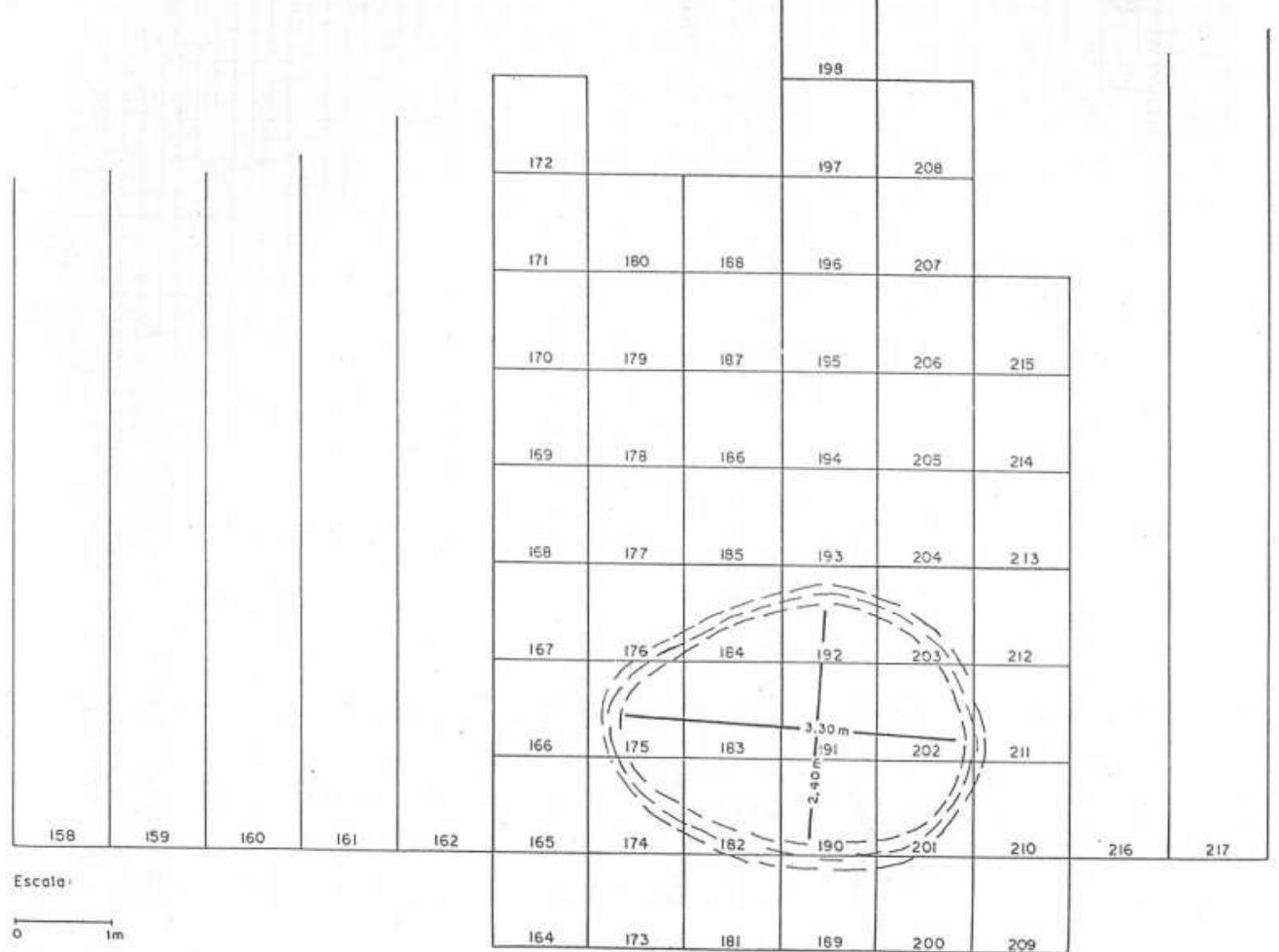




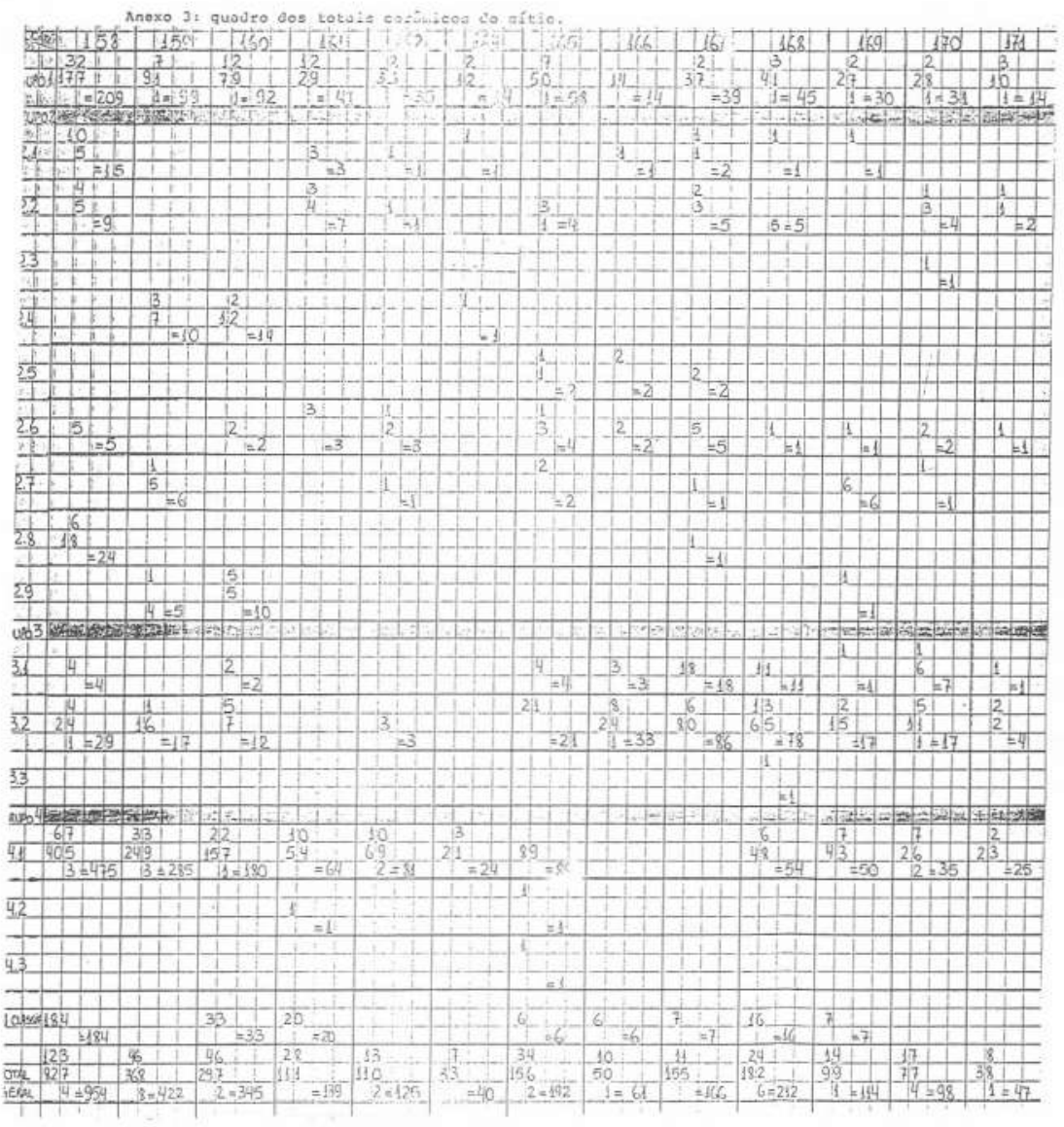




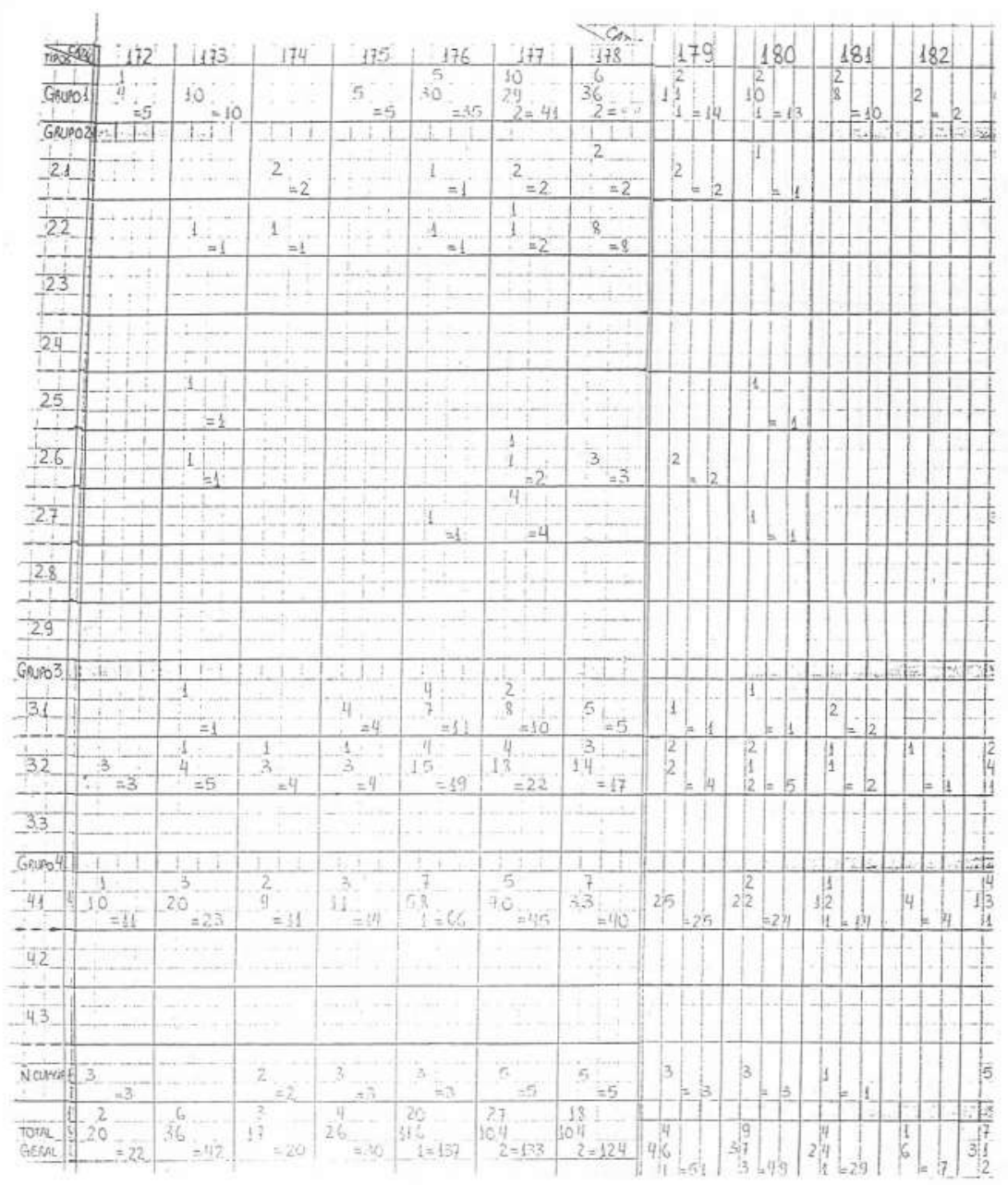




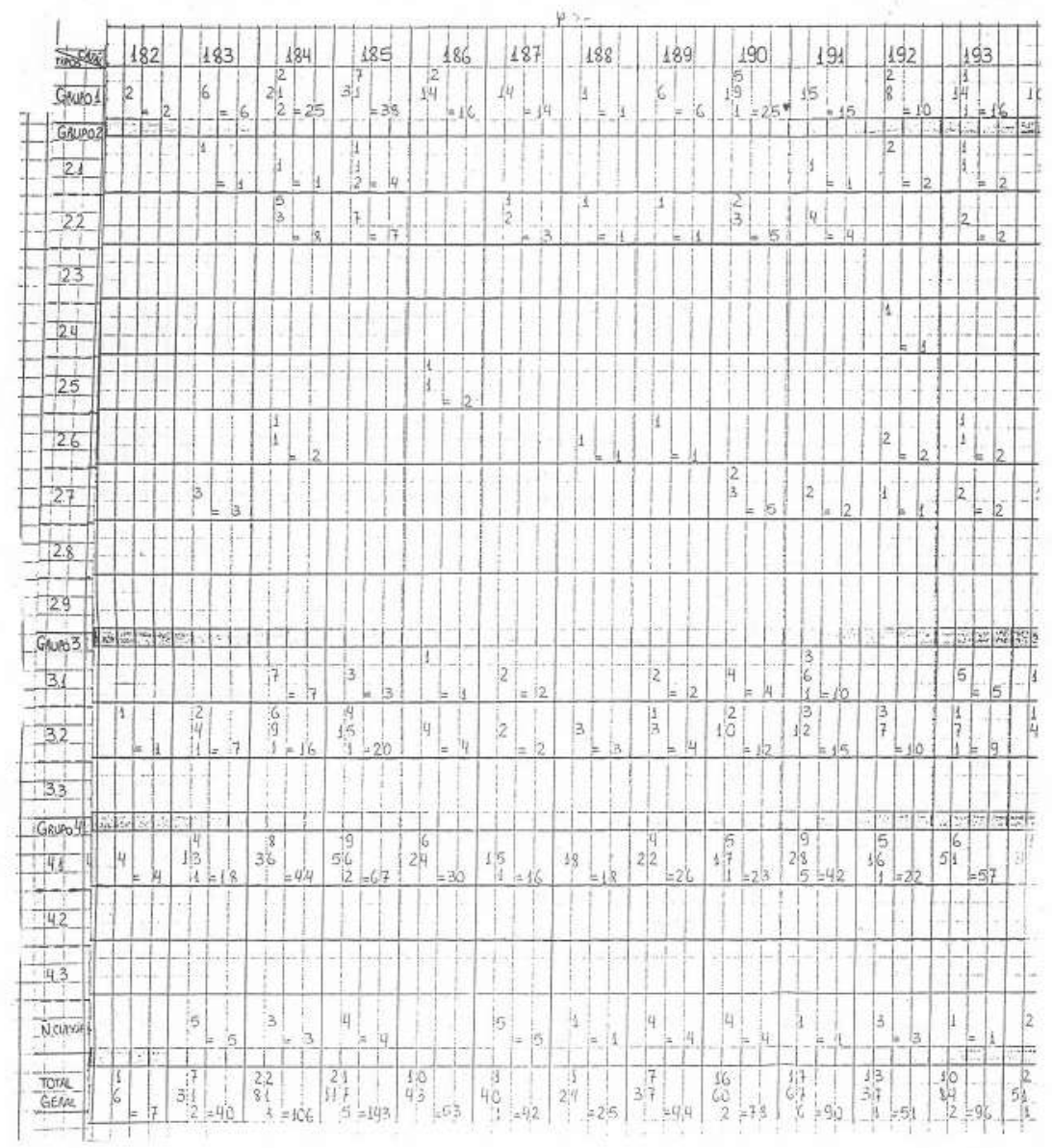




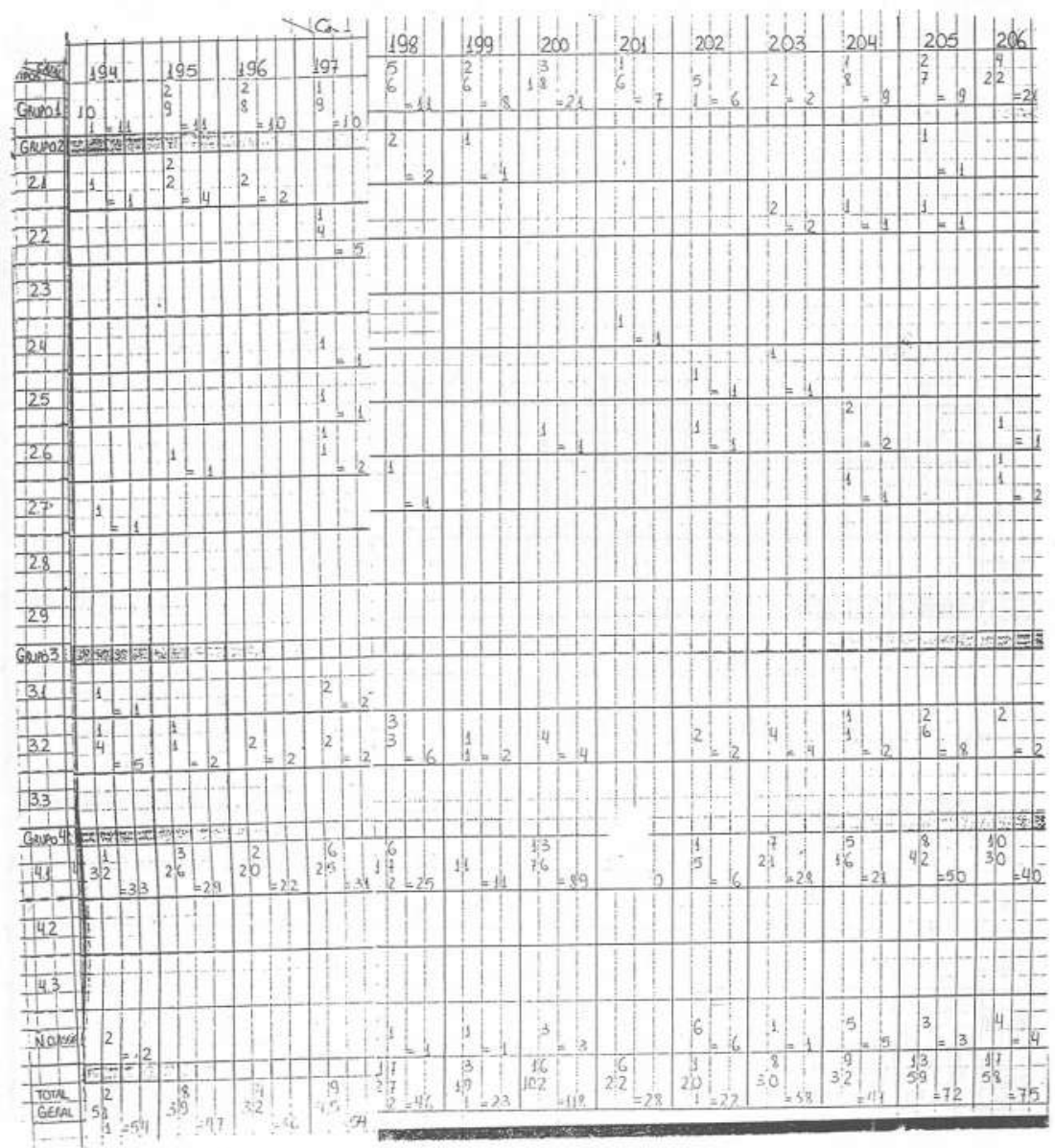




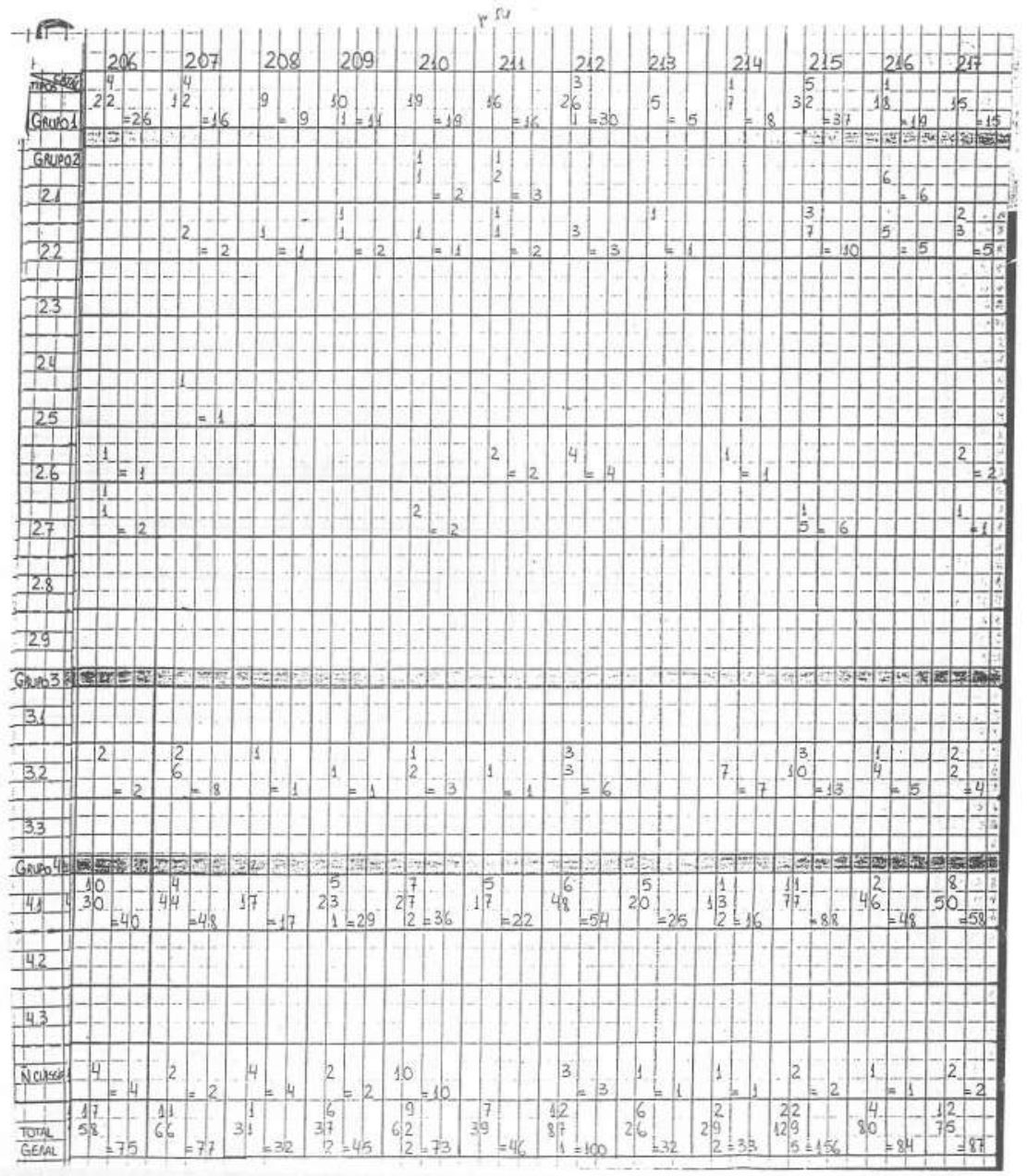




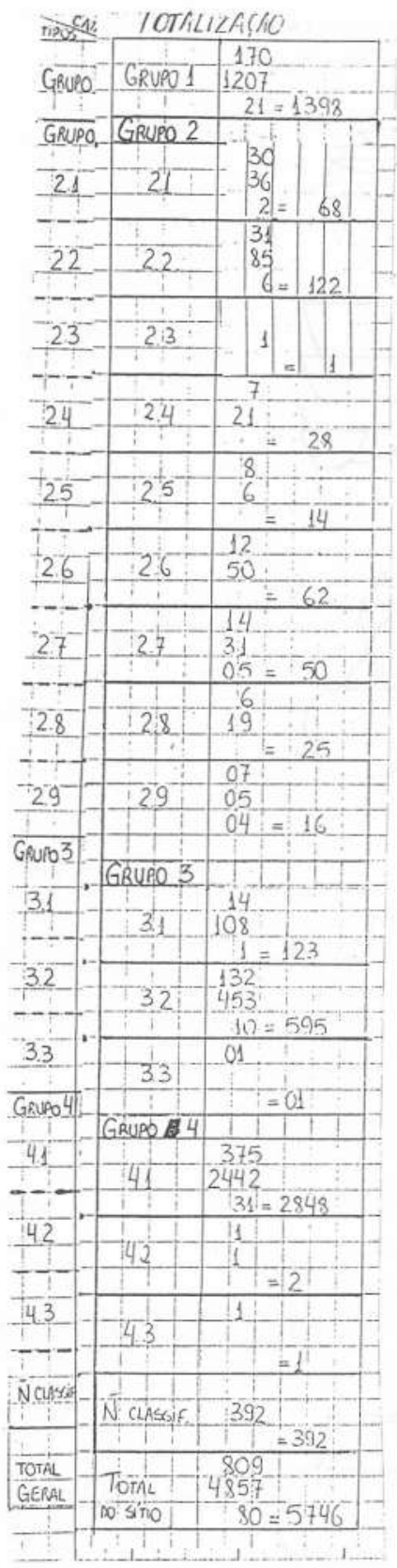


Anexo 4: formas cerâmicas encontradas no sitio.
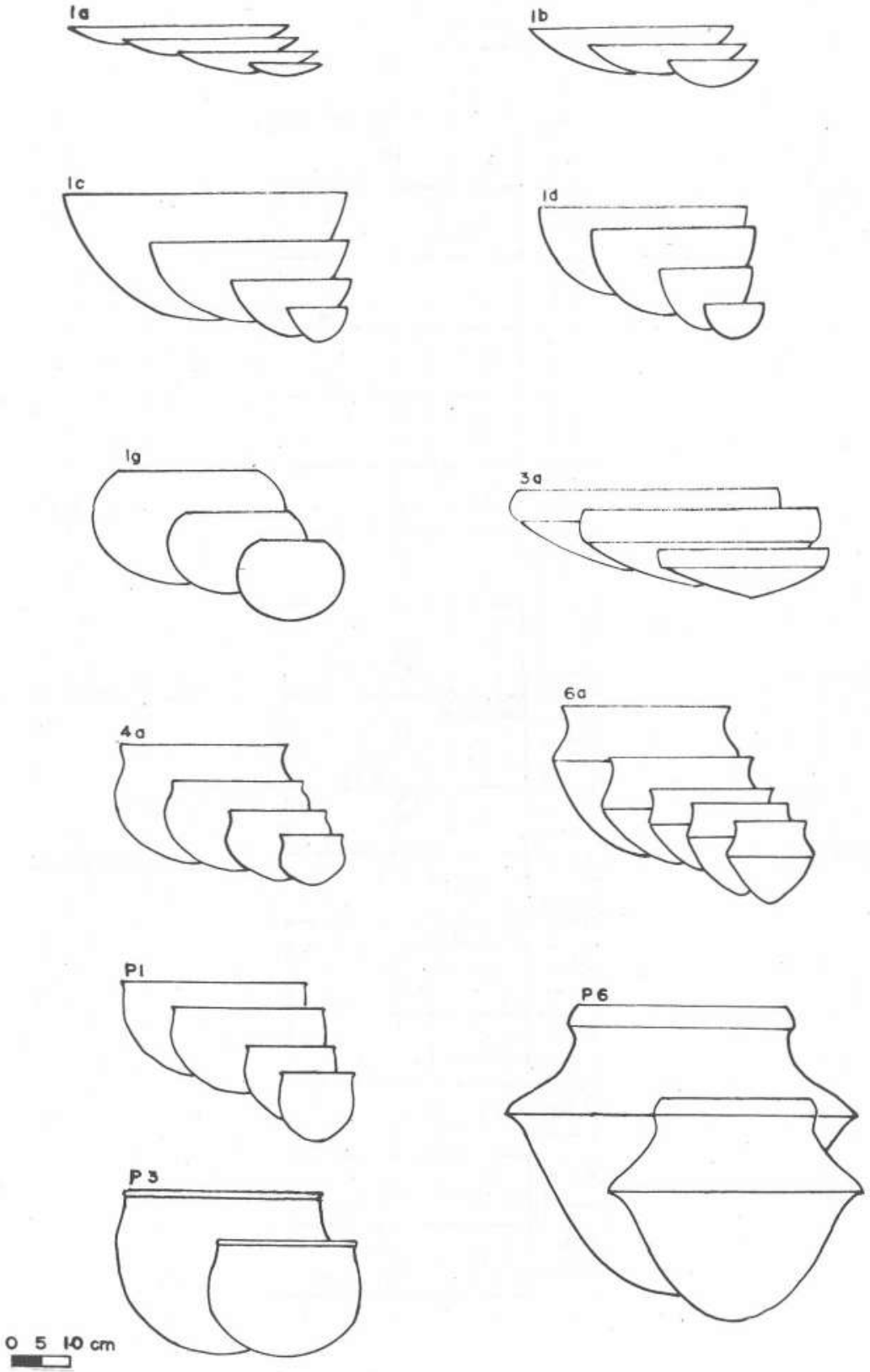
Anexo 5: formas cerâmicas encontradas no sítio.
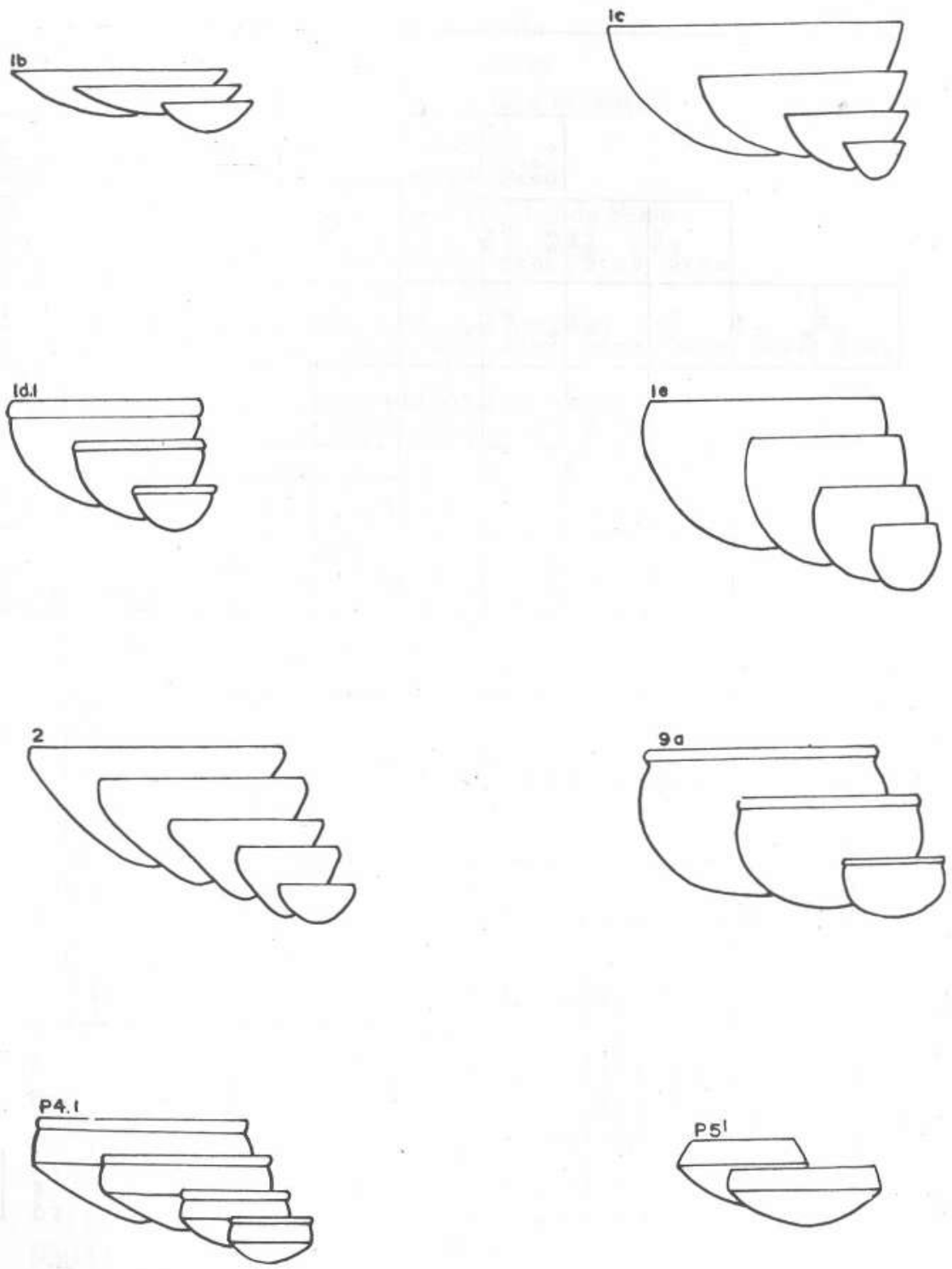

$0.510 \mathrm{~cm}$ 


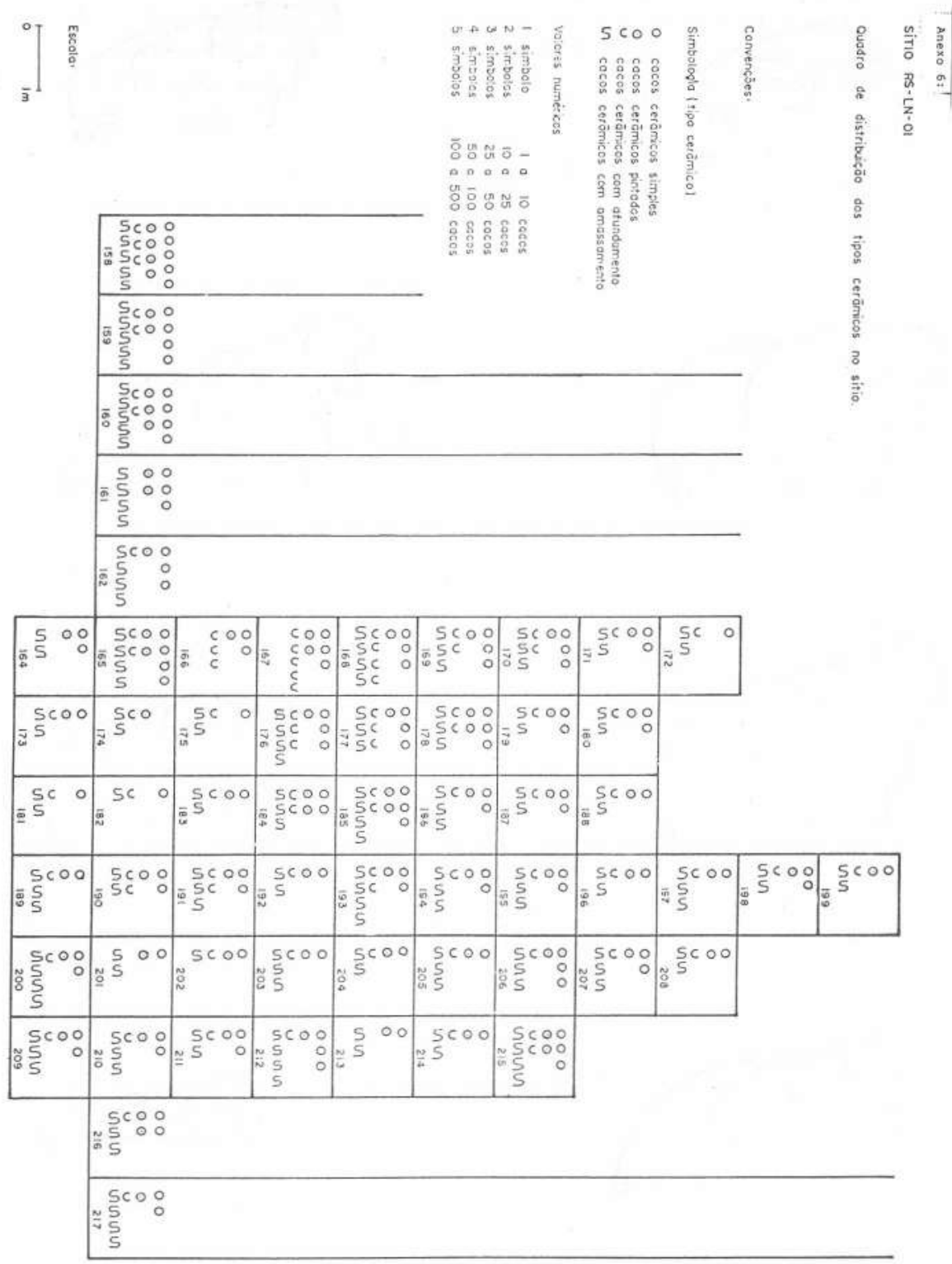


Anexo 7: listagem dos alunos do $3^{\circ}$ semestre de História da FACOS que participaram do trabalho de campo e/ou laboratório.

$\begin{array}{ll}93001 & \text { Acrides Josino de Ávila } \\ 93002 & \text { Adriane Vieira de Souza } \\ 93004 & \text { Andrea de Oliveira da Conceição } \\ 93005 & \text { Carmen Alos Pacheco } \\ 93006 & \text { Cleonice Inacio Monteiro } \\ 93007 & \text { Conceição Marques Dias da Rosa } \\ 93008 & \text { Dione Fofonka de Barcelos } \\ 93010 & \text { Eliseu da Silva Vieira } \\ 93012 & \text { Fernando de Vargas Mazuim } \\ 93014 & \text { Getúlio Silva Vargas } \\ 93023 & \text { Ilusa Cristiane Machado Jung } \\ 93022 & \text { Ilza Maria Lima Alano } \\ 93024 & \text { Isabel Teresinha Pelizoli Francisco } \\ 93025 & \text { Ivani da Silva } \\ 93017 & \text { Jairto Barbosa de Oliveira } \\ 93018 & \text { Jaqueline Tressoldi Netto } \\ 93019 & \text { João Batista Machado } \\ 93020 & \text { Jociani Barbosa Duarte } \\ 93118 & \text { Jussara Müller de Assis } \\ 93027 & \text { Lucinara Gomes Ferrari } \\ 93028 & \text { Mara Pedra Dias de Souza } \\ 93029 & \text { Marcelo Dullius Saturnino } \\ 93030 & \text { Marcelo Machado Gonçalves } \\ 93031 & \text { Marco Cesar Garcia Ribeiro } \\ 93032 & \text { Maria Conceição da Porciúncula Peixoto } \\ 93033 & \text { Maria da Silva Marques } \\ 93034 & \text { Maria de Fátima Alves Nunes } \\ 93035 & \text { Maria Gorete da Silva } \\ 93116 & \text { Maria Graciela da Fonseca Teixeira } \\ 93036 & \text { Maria Marlene de Oliveira Lopes da Silva } \\ 93037 & \text { Mariza Terezinha Maia Barcelos } \\ 93095 & \text { Moema Magni Pereira Barbosa } \\ 93115 & \text { Neiva Teresinha Vidal dos Santos } \\ 93039 & \text { Paulo Valmor Giacomelli } \\ 93040 & \text { Raul Dias da Silva } \\ 93043 & \text { Rejane Oliveira da Silveira } \\ & \\ & \end{array}$


$93041 \quad$ Rosane Silveira dos Santos

$93110 \quad$ Terezinha da Silva Moraes

93045 Valdir Guemerasca de Fraga

$93046 \quad$ Valquíria Lima Ferreira

93047 Vera Lúcia Arnesto Fagundes

$93048 \quad$ Vera Lúcia Fantinel Dalpiaz

93049 Waldir Manoel Saturnino Filho

Anexo 8: fotos do trabalho de campo.

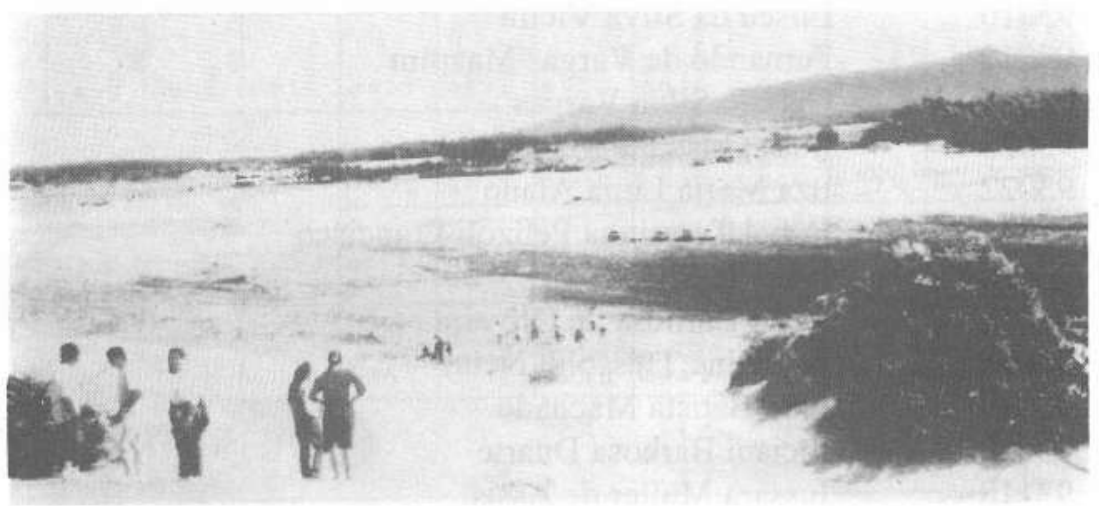

Foto 1 - Vista geral do sítio; o $1^{\circ}$ grupo faz as mediçōes, o segundo começa o quadriculamento. Ao fundo, o acesso ao sítio. 


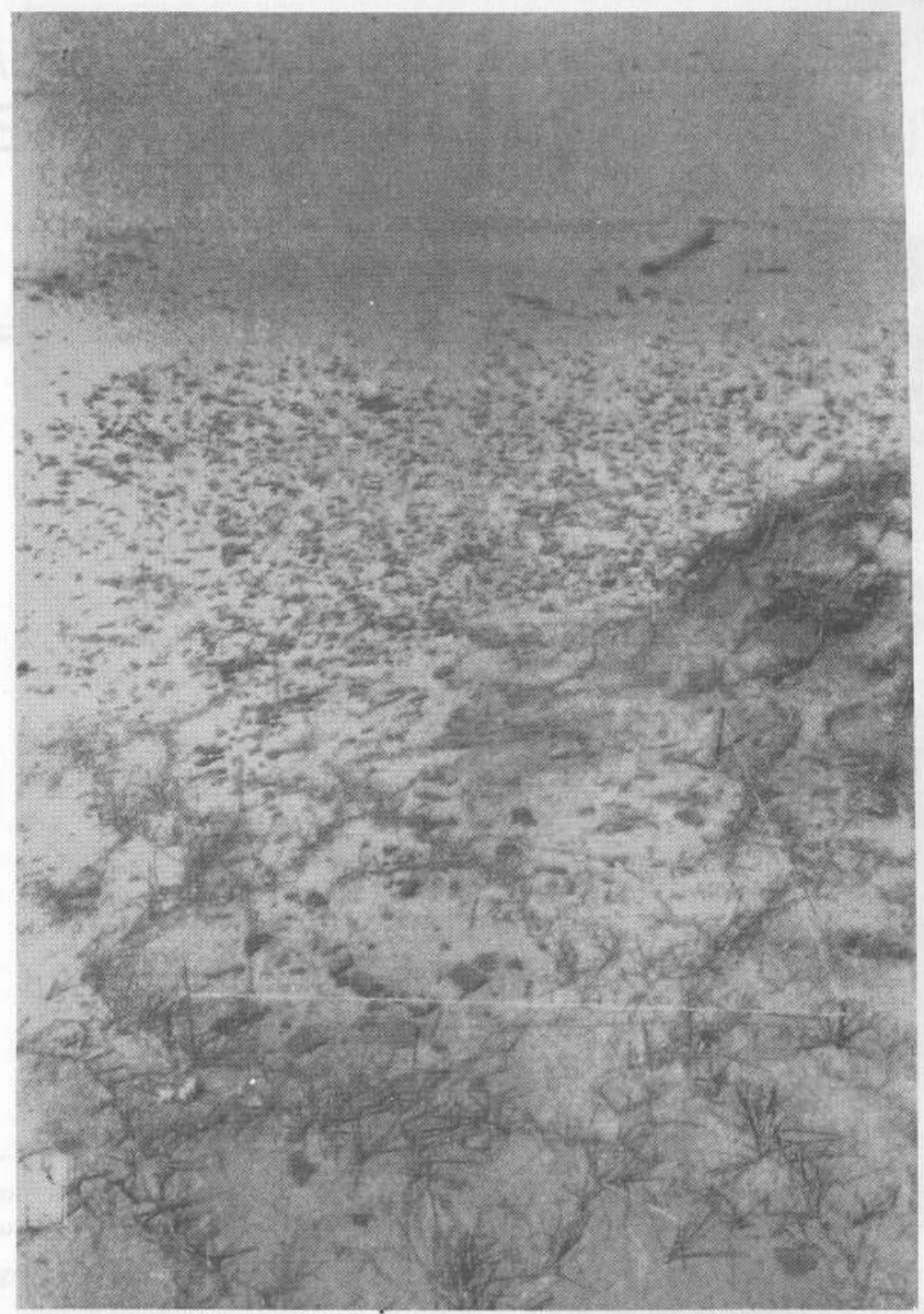

Foto 2 - Vista geral do quadriculamento. 


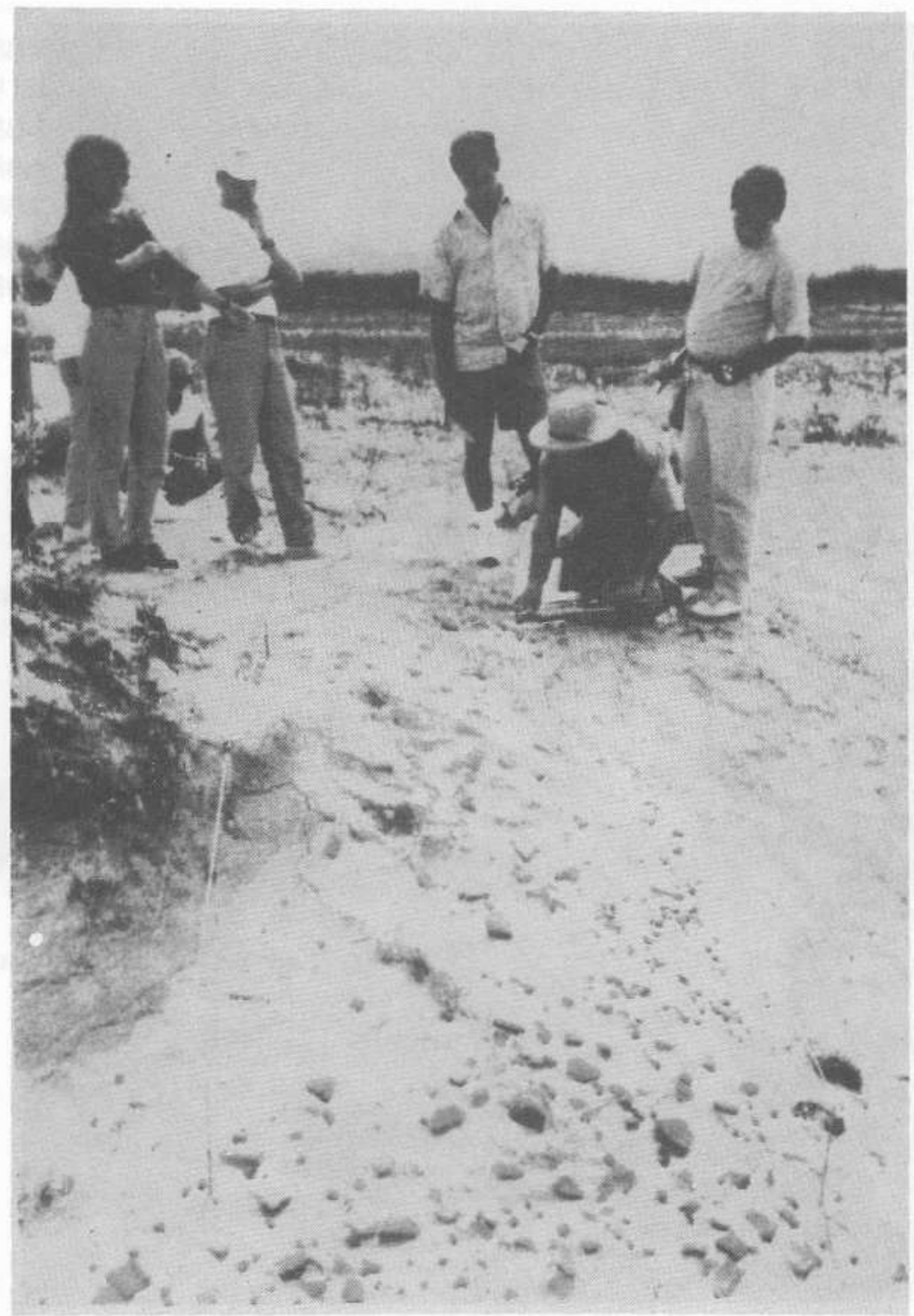

Foto 3 - Detalhe de plotação de cada peça no quadriculamento. 